\title{
Nuclear receptor profiling in prostatospheroids and castration-resistant prostate cancer
}

\author{
Zhu Wang ${ }^{1,2, *}$, Dinglan Wu $\mathbf{u}^{1,3, *}$, Chi-Fai Ng${ }^{4}$, Jeremy Yuen-Chun Teoh ${ }^{4}$, Shan Yu1, Yuliang Wang ${ }^{1}$ and \\ Franky L Chan'
}

1School of Biomedical Sciences, The Chinese University of Hong Kong, Hong Kong, China 2Department of Urology, People's Hospital of Longhua, Shenzhen, China

${ }^{3}$ The Clinical Innovation \& Research Center, Shenzhen Hospital, Southern Medical University, Shenzhen, China

${ }^{4}$ Department of Surgery, Faculty of Medicine, The Chinese University of Hong Kong, Hong Kong, China

Correspondence should be addressed to Y Wang or F L Chan: yuliang.wang816@gmail.com or franky-chan@cuhk.edu.hk

*(Z Wang and D Wu contributed equally to this work)

\begin{abstract}
Nuclear receptors (NRs), which belong to a superfamily of transcription factors and consist of a total of $\mathbf{4 8}$ members in humans, govern the expression of genes involved in a board range of developmental, reproductive, metabolic and immunological programs. Given the significant importance of androgen receptor and a few known NRs in the progression of prostate cancer, we surveyed the expression profiles of the entire NR superfamily in three-dimensional cultured prostatospheroids derived from different prostate cancer cell lines and a tumor xenograft model of castration-resistant prostate cancer VCaP-CRPC by quantitative real-time RT-PCR. Our results revealed that prostatospheroids and castration-relapse VCaP-CRPC xenografts, both contained enriched populations of prostate cancer stem/progenitor-like cells (PCSCs), displayed distinct expression patterns of NRs. Intriguingly, most of these differentially expressed NRs were orphan NRs and showed upregulation. Pairwise analysis identified five orphan NRs (including ROR $\beta$, TLX, COUP-TFII, NURR1 and LRH-1) that showed common upregulation in both mRNA and protein levels in the prostatospheroids and castration-relapse VCaPCRPC xenografts, and overexpression of these orphan NRs could increase cancer stem cell marker expressions and enhance spheroid formation capacity in prostate cancer cells, suggesting that these orphan NRs might perform positive roles in the growth regulation of PCSCs and castration-resistant prostate cancer. Together, our NR expression dataset not only revealed the distinct physiologic status and regulatory roles governed by the networks of specific NRs but also some of these identified orphan NRs could be the potential therapeutic targets for PCSCs or castration-resistant prostate cancer.
\end{abstract}
Key Words
- nuclear receptors
- orphan nuclear receptors
- prostate cancer
- castration resistance
- prostate cancer stem-like cells

Endocrine-Related Cancer (2018) 25, 35-50

\section{Introduction}

It is well established that the normal and neoplastic growth of prostate gland is significantly driven by androgen via its cognate androgen receptor (AR). Based on this androgen-dependent characteristic, it forms the biological basis of hormone therapy for prostate cancer (androgen deprivation by castration or AR-axis targeted therapy by antiandrogens) by targeting mainly the AR-axis signaling, as proposed originally by Huggins 
and Hodges in the 1940s (Huggins \& Hodges 1941) and remains the frontline treatment option for the advanced prostate cancer. It is also recognized that dysregulation of AR signaling and androgen metabolism, including AR hypersensitivity to castration levels of androgens due to AR overexpression or antagonist-to-agonist switch due to AR mutation and intra-tumoral androgen biosynthesis, are critically involved in its advanced progression to androgen-insensitive and metastatic stages (castration-resistant or hormone-refractory prostate cancer CRPC) and are also believed to be the main causes for the failure of hormone therapy (Yuan et al. 2014, Karantanos et al. 2015). Targeting these compensatory mechanisms that allow reactivation of AR-axis signaling in therapy-resistant patients, novel antiandrogen (enzalutamide) and androgen biosynthesis inhibitor (CYP17A1-targeting abiraterone acetate) have been recently developed and applied as novel AR-axistargeted therapies. The clinical outcomes by these novel hormone therapies show significant improvement on overall survival in patients with metastatic CRPC (Ryan et al. 2015). Despite these advances, adopted secondary resistance to enzalutamide or abiraterone soon develops in patients and such resistance is shown to involve the expression of AR splice variants, particularly the constitutively active ligand-binding domain (LBD) deleted AR-V7 (Antonarakis et al. 2014). Furthermore, detection of AR-V7 variant or mutated AR in circulating tumor cells or cell-free serum is shown useful to predict the treatment response or prognosis of CRPC patients (Steinestel et al. 2015, Lallous et al. 2016). In some CRPC patients, the disease will evolve to a highly aggressive and treatment-resistant CRPC, characterized by acquired neuroendocrine cell-specific phenotype and loss of AR, of which treatment option is limited and results in high mortality. Accumulating pieces of evidence suggest that prostate cancer stem/progenitor-like cells (PCSCs, also called prostate cancer stem cells, tumor initiating or progenitor cells) may contribute to the advanced growth of metastatic CRPC. The mechanisms and signaling pathways involved in the growth regulation of PCSCs are still largely unclear. Therefore, it is of utmost importance to identify novel therapeutic targets for the advanced therapy-resistant prostate cancer.

Nuclear receptors (NRs) belong to a superfamily of DNA-binding transcription factors and consist of a total of 48 members in humans. They comprised the commonly conserved modular DNA-binding domain and C-terminal LBD. Studies in past decades indicate that they play important regulatory roles virtually in all biological processes and cellular functions, and are also involved in many diseases. Thus, many NR members are promising drug targets or being used as established therapeutic targets for different diseases, including diabetes and cancers. Based on the presence or absence of physiological ligands, NRs are generally grouped into hormone receptors, adopted orphan receptors and genuine orphan receptors (Chawla et al. 2001). Indeed, besides AR, many members of NR superfamily are also expressed in human prostate gland and prostate cancer cells (Cheung et al. 2005). Some hormone NRs are shown to play multiple roles in the prostate cancer progression and their pharmacological manipulation can therapeutically intervene the growth of prostate cancer. For example, glucocorticoid receptor (GR) can act to antagonize AR signaling in prostate cancer and glucocorticoid treatment is either used singly or in combination with chemotherapy and abiraterone acetate for metastatic CRPC (Sahu et al. 2013, Kach et al. 2015). Vitamin D receptor (VDR) can crosstalk with AR and its activation can modulate androgen metabolism and suppress prostate cancer cell proliferation via different mechanisms (Ahn et al. 2016). Use of calcitriol (active vitamin D3 metabolite) in combination with chemotherapy can exert certain beneficial effects on some CRPC patients, though not clinically and fully established yet (Ben-Eltriki et al. 2016). Recent advances show that some orphan NRs, including ROR $\gamma$ (NR1F3) (Wang et al. 2016), TRs (NR2C1, NR2C2) (Mu \& Chang 2003, Lin et al. 2015), TLX (NR2E1) (Wu et al. 2015), COUP-TFII (NR2F2) (Qin et al. 2013), ERRs (NR3B1/2/3) (Yu et al. 2007, 2008, Zou et al. 2014), NGFI-B (NR4A1) (Yu et al. 2014), DAX1 (NROB1) (Agoulnik et al. 2003) and SHP (NROB2) (Yuan et al. 2001), can either promote or suppress prostate cancer growth via their diverse AR-associated or -independent signaling pathways. Intriguingly, it is shown that some orphan NRs may have potential therapeutic values for prostate cancer as modulation of their activities by ligands or small molecules could suppress the growth of prostate cancer cells.

The quantitative RT-PCR has been used to characterize and quantify the expression profiles of the entire NR superfamily in certain human organs (Nishimura et al. 2004), some specific cell types and their differentiation status (including immune cells (Schote et al. 2007), adipocytes and adipogenesis (Lahnalampi et al. 2010), fat-accumulated hepatocytes and hepatoma cells 
(Moya et al. 2010)), embryonic stem cells (Xie et al. 2009) and also a few cancer types (including lung cancer (Jeong et al. 2010), colon cancer (Modica et al. 2009) and breast cancer stromal cells (Knower et al. 2013)). The expression profile datasets of NRs as disclosed in these studies not only can provide an insight into the networks of signaling pathways regulated by multiple NRs but also help to identify whether some of the NRs could serve as specific biomarkers or perform certain regulatory roles in the organs or cellular differentiation processes, and also importantly as potential prognosis markers or therapeutic targets for cancers. Given the importance of AR and a few known NRs in regulating prostate cancer growth, we here sought to profile the expression patterns of the entire NR superfamily in three-dimensional (3D) cultured prostate cancer cell line-derived prostatospheroids, which were enriched in PCSCs and also a xenograft model of CRPC using the quantitative real-time RT-PCR (qRT-PCR) in order to provide a comprehensive view on the expression profiles of NR superfamily in these in vitro and in vivo prostate cancer models. Our results identified some orphan NRs which exhibited common expression in both prostatospheroids and castration-relapse CRPC xenografts.

\section{Materials and methods}

\section{Cell lines}

Prostate cancer cell lines LNCaP and DU145 were obtained from ATCC and VCaP from Prof. K Pienta. Cells were grown in RPMI 1640, MEM and DMEM, respectively, supplemented with 10\% FBS and antibiotics (1\% penicillin and streptomycin) under conventional 2-dimensional (2D) culture conditions (Wu et al. 2015). All culture reagents and supplements were obtained from Invitrogen.

\section{Sphere formation assay}

Subconfluent cultured cells were trypsinized, washed twice with PBS, suspended in DMEM/F12K medium (supplemented with $10 \mathrm{ng} / \mathrm{mL}$ epidermal growth factor, $10 \mathrm{ng} / \mathrm{mL}$ basic fibroblast growth factor, $2 \%$ B-27 supplement, $5 \mu \mathrm{g} / \mathrm{mL}$ insulin, $1 \%$ knockout replacement serum and $1 \%$ penicillin and streptomycin) and seeded at $10^{3}$ cells $/ \mathrm{mL}$ onto ultra-low attachment plates (Corning) and cultured at $37^{\circ} \mathrm{C}$ for 2 weeks, with fresh medium replaced every 2-3 days after the first 5-day culture. Spheres or prostatospheroids at sizes over $80 \mu \mathrm{m}$ were scored and harvested for expression assays.
Establishment of castration-resistant prostate cancer tumor xenografts

VCaP cells $\left(2 \times 10^{6}\right.$ cells $/ 100 \mu \mathrm{L}$ mixed 1:1 in Matrigel $)$ were injected subcutaneously into the flanks of 6-8-week-old intact male SCID mice and allowed to grow for 14 weeks totally. Host-mice-bearing tumor xenografts were then orchiectomized when tumor sizes reached about $0.8 \mathrm{~cm}^{3}$. The relapsed tumor xenografts were allowed to grow to sizes of about $1.2 \mathrm{~cm}^{3}$. In some host-mice-bearing relapse tumors, animals were further treated with abiraterone $(0.5 \mathrm{mmol} / \mathrm{kg} / \mathrm{day})$ for 3 weeks. Needle biopsies of tumor xenografts were acquired on same days when castration was performed (pre-castration), 4-day post-castration and 8-week post-castration (castration-relapse) for mRNA and flow cytometry analyses.

\section{RNA extraction and qRT-PCR analysis}

Total RNA was extracted from cultured cells and tumor xenografts using TRIzol reagent, and treated with DNaseI. First-strand cDNA was synthesized with $1 \mu \mathrm{g}$ RNA using PrimeScript RTase and a mixture of oligo-dT and random hexamers (PrimeScript RT Master Mix, TaKaRa) at $37^{\circ} \mathrm{C}$ for $15 \mathrm{~min}$, followed by heat inactivation of RTase at $85^{\circ} \mathrm{C}$ for $5 \mathrm{~s}$. qRT-PCR was performed using an SYBR green fluorescencebased method. Briefly, PCR reactions were assembled by mixing $25 \mathrm{ng}$ of cDNA, $150 \mathrm{nM}$ of primer pairs and SYBR green master mix (SYBR Premix Ex Taq, ROX Plus, TaKaRa) and was performed in a real-time PCR system (StepOne, Applied Biosystems) at $95^{\circ} \mathrm{C}$ for $20 \mathrm{~s}$, followed by 40 threestep cycles of $95^{\circ} \mathrm{C}$ for $15 \mathrm{~s}, 60^{\circ} \mathrm{C}$ for $20 \mathrm{~s}$ and $72^{\circ} \mathrm{C}$ for $30 \mathrm{~s}$. We also evaluated the expressions of totally 10 housekeeping genes in prostatic cells cultured at different conditions using validated PCR primer sets (RealTimePrimers.com) in order to identify the appropriate housekeeping gene for qRTPCR analysis. Results showed that all tested housekeeping genes, including $\beta$-actin, exhibited same expressions levels in both adherent cultured cells and prostatospheroids (Supplementary Fig. 1, see section on supplementary data given at the end of this article). Relative mRNA levels were determined using the comparative $\Delta-\mathrm{CT}$ method and normalized against $\beta$-actin. The specificity of the primers was validated by the melting-curve detection. mRNA levels with cycle threshold (CT) values $\geq 34$ were considered as below detection (Bookout et al. 2006, Jeong et al. 2012). Primer sequences for all NRs and cancer stem-like cell biomarkers, and the mean PCR-amplification CT values of all NRs expressed in 2D-monolayer prostate cancer cells are listed in Supplementary Tables 1, 2, 3, 4, 5 and 6. 


\section{Plasmid construction and lentiviral transduction}

Full-length cDNAs of human ROR $\beta, T L X$, COUP-TFII, NURR1 and LRH-1 were amplified by PCR using plasmid clones obtained from DNASU Plasmid Repository (Arizona State University), FLAG-tagged and subcloned into lentiviral plasmid pWPI for overexpression study. For production of lentiviruses, constructed or empty pWPI plasmids were transfected into 293FT packaging cells. To generate stable infectants, LNCaP and DU145 cells were infected with orphan NR-expressing viruses following procedures as described previously (Wu et al. 2015). The generated infectants were validated by RT-PCR and immunoblot analyses before use.

\section{Immunoblotting}

Whole cell proteins were extracted from subconfluent cultured cells, isolated spheres and re-adherent cells from spheres using a cold lysis buffer (20 mM PIPES, 0.1\% SDS, $1 \mathrm{mM}$ EDTA, $1 \mathrm{mM}$ EGTA, $10 \mathrm{mM}$ monothioglycerol, $1 \mathrm{mM}$ PMSF, $5 \mathrm{mM}$ leupeptin, $0.25 \mathrm{M}$ sucrose). After SDS-PAGE separation and transblotting onto PVDF membranes, resolved proteins were probed with optimally diluted primary and secondary antibodies followed by a chemiluminescent detection method (ECL Western Blotting Detection System, Amersham). Primary antibodies used are as follows: ROR $\beta$ (EPR15552, Abcam), TLX (Wu et al. 2015), COUP-TFII (H7147, Abcam), NURR1 (N1404, Abcam) and LRH-1 (H2325, Abcam).

\section{Immunofluorescence}

Cryostat sections of OCT-embedded and frozen tumor xenografts were fixed with $4 \%$ paraformaldehyde, membrane-permeabilized with PBS-buffered 0.1\% Triton X-100 and blocked with 5\% normal goat serum, followed by staining with primary FITC-conjugated CD44antibody (\#130-095-195, Miltenyi Biotec $\mathrm{GmbH}$ ) at $4^{\circ} \mathrm{C}$ overnight in dark and nuclear counterstained with DAPI. Immunofluorescence was performed using a confocal microscope system (Olympus FV1000) as described previously (Yu et al. 2014).

\section{Flow cytometry analysis}

Prostate cancer cells harvested from minced tumor xenografts and high-grade prostate cancer clinical tissues $(n=5)$ were dissociated into single-cell suspension by filtering through a $40-\mu \mathrm{m}$ cell strainer, collected by low-speed centrifugation and re-suspended in PBS before flow cytometry analysis. For fluorescence-activated cell sorting (FACS), $10 \times 10^{6}$ viable suspended cells, pre-blocked with 1\% BSA, were stained with PBS-buffered FITCconjugated CD44 antibody and APC-conjugated CD133 antibody (\#130-095-195, \#130-097-049, Miltenyi Biotec $\mathrm{GmbH})$ for $10 \mathrm{~min}$ at $4^{\circ} \mathrm{C}$ to sort out the CD $44^{+} / \mathrm{CD} 133^{+}$ cell populations using a flow cytometer (Beckman Coulter FC500 MCL/MPL Counter). At least three independent experiments were performed on each sample.

\section{ONCOMINE oncogenomic analysis}

The differential mRNA expression levels of NRs identified in our models were validated in prostate cancer clinical samples and normal prostate gland tissues using TCGA datasets in ONCOMINE database (http://www.oncomine. org). The parameters used for the analysis include the official gene names of the NRs as primary filter, and the expression levels in cancer versus normal tissue as analysis type. The threshold used to obtain the most significant probes of the queried gene for each microarray data included a two-fold difference in expression between cancers and normal tissues with a $P$ value $<1 \times 10^{-4}$.

\section{Data analysis}

The relative fold changes (RFC) of mRNA levels were determined by the comparative threshold cycle method $(2-\Delta \Delta \mathrm{Ct})$ and normalized to $\beta$-actin. NR mRNA levels with cycle times $\geq 34$ were considered as beyond detection. NR mRNA levels with RFC $\geq 2.0$ were interpreted as upregulation and with RFC $\leq 0.5$ as downregulation as compared to their reference samples, whereas with RFC within 0.5-2.0 were considered as not significantly and statistically different from that of reference sample. Data analysis and normalization to control gene expression were performed with the SDS2.2 software (Applied Biosystems). Data were expressed as mean \pm s.D. Wilcoxon non-parametric test was utilized for statistical analysis and a $P$ value $<0.05$ was considered statistically significant.

\section{Results}

\section{PCSC-enriched prostatospheroids exhibit increased} expression of stem-like cell markers

It is well characterized that cellular aggregates or spheroids formed under the non-adherent 3D-culture condition from single-cell suspensions derived from various primary 
or tumor tissues are enriched in stem or progenitor cells (Pastrana et al. 2011), likely due to their anchorageindependent growth capacity. Based on this, single-cellbased and non-adherent sphere formation assays have been widely used to identify and isolate the putative prostatic stem-like cells or PCSCs derived from various in vitro and in vivo prostatic sources for self-renewal and differentiation analyses (Li et al. 2009, Lukacs et al. 2010). Here, we performed the sphere formation assay on three established prostate cancer cell lines differing in their AR expression status (AR-positive: LNCaP and VCaP; AR-negative: DU145) in order to enrich the PCSCs for entire NR member expression analysis. Results of qRT-PCR analysis showed that the isolated spheroids or prostatospheroids derived from different prostate cancer cell lines exhibited significantly increased expression levels of PCSC markers as compared to their parental cells grown under the conventional 2D adherent condition, indicating that these prostatospheroids were enriched in PCSCs (Fig. 1).
Prostatospheroids display distinct expression profiles of NRs

Increasing pieces of evidence indicate that certain members of NR superfamily play important roles in the regulation of stemness and differentiation of both embryonic stem cells and various types of adult tissue-specific stem cells (Jeong \& Mangelsdorf 2009). In order to identify the members of NR superfamily, which would be involved in prostatospheroid formation or play roles in the growth of PCSCs, we determined the expression profiles of the total 48 NR members in prostatospheroids derived from three prostate cancer cell lines by the qRT-PCR method, which can assess the relative expression levels of NR transcripts and also their changes of levels in prostate cancer cells upon hormone manipulation. Results showed that a broad range of NRs, particularly the orphan NR members, were expressed in both adherent cultured prostate cancer cells and PCSC-enriched prostatospheroids. Analysis of
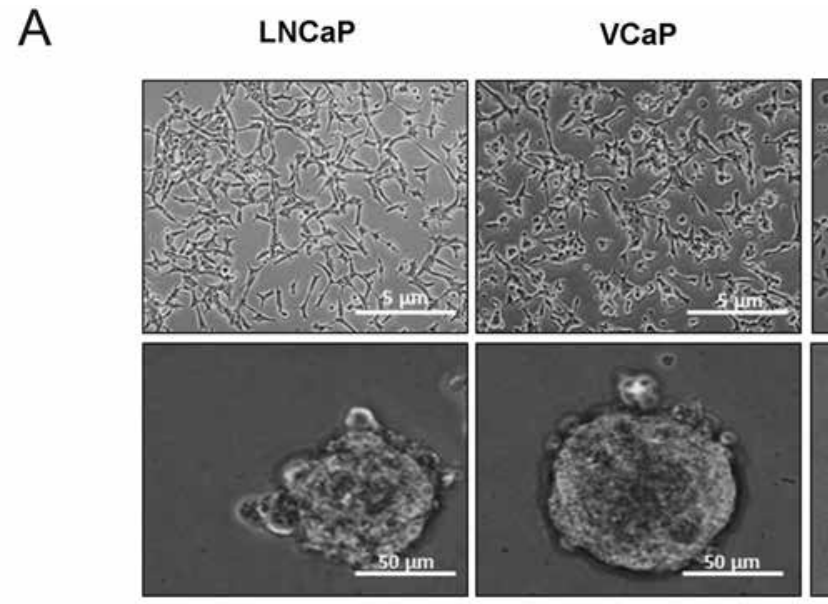

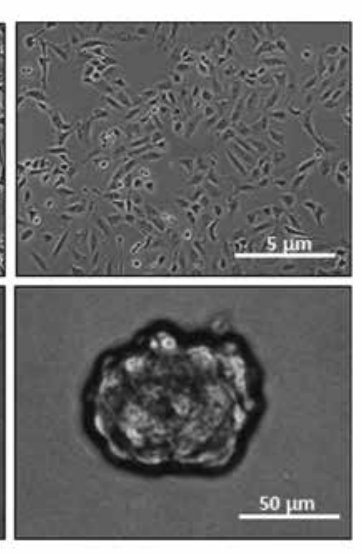

\section{Adherent \\ cells}

Spheroids

B
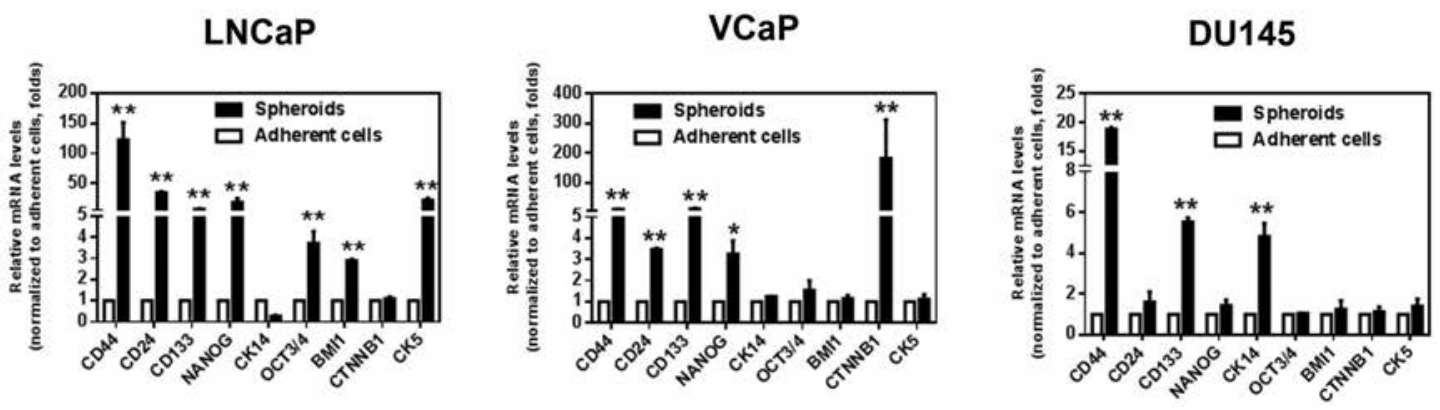

Figure 1

Prostate cancer cell line-derived prostatospheroids display enhanced expression of PCSC-associated markers. (A) Representative images of three selected prostate cancer cell lines (AR-positive: LNCaP and VCaP; AR-negative: DU145) grown under the conventional 2D-adherent culture conditions and their corresponding single-cell-derived prostatospheroids formed under the non-adherent 3D-culture conditions. (B) qRT-PCR analysis. Results showed that the expression levels of PCSC-associated markers were significantly upregulated in prostatospheroids. Fold changes of expression levels of PCSC-associated markers expressed in prostatospheroids were normalized to that in adherent $2 \mathrm{D}$-cultured cells. ${ }^{*} P<0.05 ; * * P<0.01$ vs corresponding $2 \mathrm{D}$-cultured cells. 
expression profiles of NR members in prostatospheroids further revealed that a total of 33 NRs were significantly upregulated in LNCaP-prostatospheroids, 27 NR members in VCaP-prostatospheroids and 36 NR members in DU145prostatospheroids (Fig. 2A, B and C). Further analysis identified that among these NRs with increased expressions, 21 members exhibited common upregulation pattern in prostatospheroids derived from three prostate cancer cell lines. These included 3 endocrine NRs, 3 adopted NRs and 15 ligand-independent orphan NRs (listed in Fig. 2D).
A

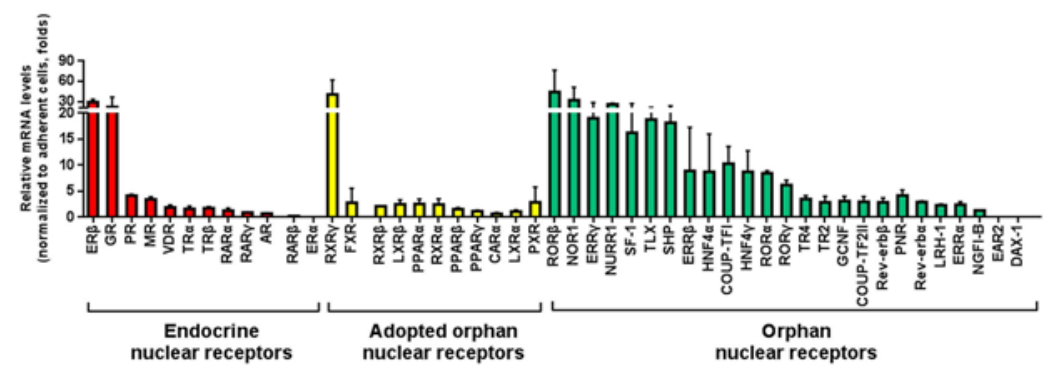

B

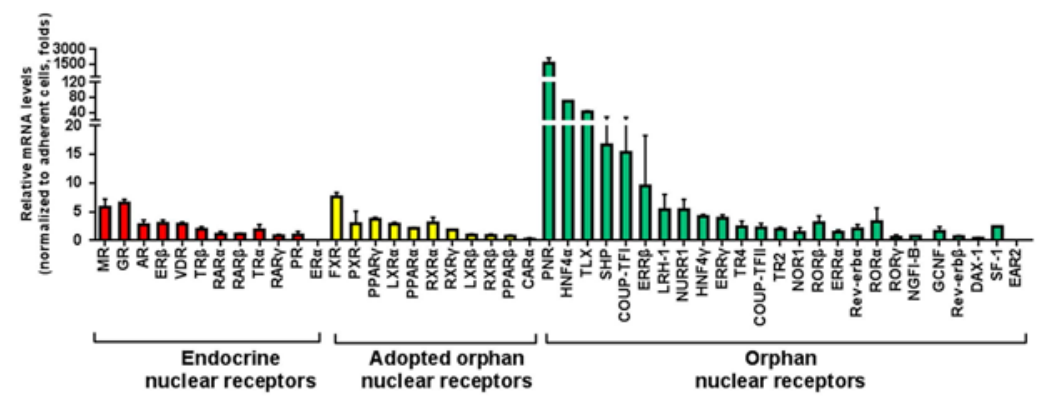

C

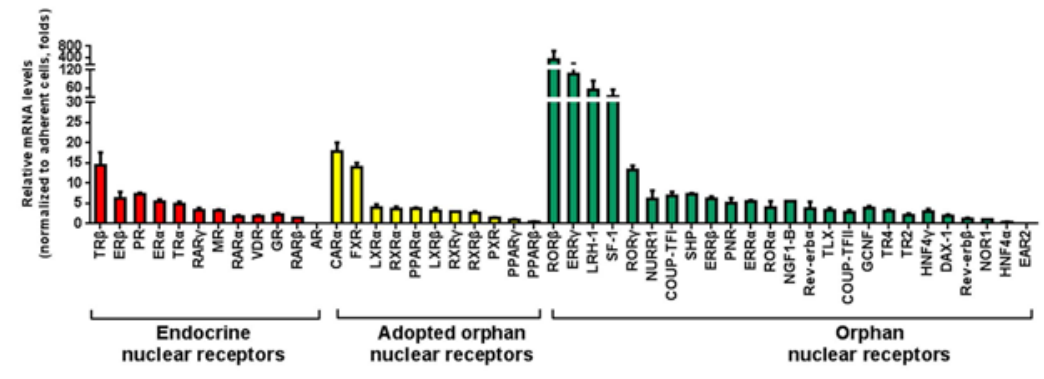

D
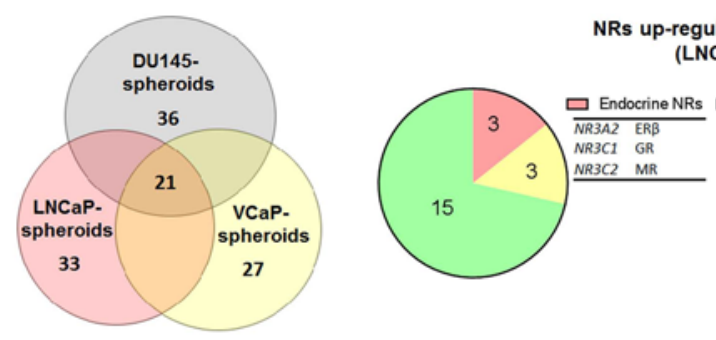

(LNCaP, VCaP, DU145)

s Adopted orphan NRs $\square$ Orphan NRs \begin{tabular}{ll}
\hline NR1C1 & PPARQ \\
NR1H4 & FXR \\
\hline
\end{tabular} \begin{tabular}{lll} 
NR1H4 & FXR \\
NR2B1 & RXRG \\
\hline
\end{tabular} \begin{tabular}{ll}
\hline CIphan NRs \\
\hline NROB2 & SHP \\
NR1D1 & Rev-erba
\end{tabular} NR1F1 RORA NRIF2 RORB $\begin{array}{ll}\text { NR2A2 } & \text { HNF4V } \\ \text { NR2C2 } & \text { TR4 }\end{array}$ $\begin{array}{ll}\text { NR2C2 } & \text { TR4 } \\ \text { NR2E1 } & \text { TLX }\end{array}$ NR2E3 PNR $\begin{array}{ll}\text { NR2F1 } & \text { COUP.TFI } \\ \text { NR2F2 } & \text { COUP-TFI }\end{array}$ NR3B2 ERRB NR3B3 ERRY NRAA2 NURR1 \begin{tabular}{ll} 
NRSA1 & SF-1 \\
NRSA2 & LRH-1 \\
\hline
\end{tabular}
Figure 2

Prostatospheroids display distinct expression profiles of NRs. (A, B and C) Histograms show the relative fold changes (RFC) of expressions of NRs in prostatospheroids derived from (A) LNCaP, (B) VCaP and (C) DU145 prostate cancer cell lines. NRs are grouped according to their ligand dependence as endocrine, adopted and orphan NRs. RFC of NR expressions were normalized to that in adherent 2D-cultured parental cells. The normalized NR expression levels are defined as upregulated if $\mathrm{RFC}$ values are $\geq 2.0$, downregulated if $R F C$ values $\leq 0.5$, no significant change if RFC values within $0.5-2.0$, and undetected if $\mathrm{Ct}$ value $>34$. Results showed that many members of NRs showed significant upregulation in prostatospheroids. (D) Left: data analysis summarized that a total of 21 NR members exhibited common upregulation in prostatospheroids derived from three prostate cancer cell lines. Middle: pie chart shows the number of endocrine, adopted and orphan NRs with common upregulation in prostatospheroids. Right: table shows the trivial and gene names of upregulated NRs in prostatospheroids. 
Results also identified that some NR members exhibited diametrical expression patterns in prostatospheroids derived from different cancer cell lines. For example, HNF4 $\alpha$ showed significant upregulation in both LNCaPand VCaP-prostatospheroids but downregulation in DU145-prostatospheroids; TR $\alpha$ and TR $\beta$ showed significant upregulation in DU145-prostatospheroids but no change in LNCaP- and VCaP-prostatospheroids, suggesting that these NRs might perform cell functions on spheroid formation in a cell-dependent manner. We also observed that only few NRs displayed downregulation in prostatospheroids (Supplementary Fig. 2). However, no common expression patterns were observed among these downregulated NRs in prostatospheroids (such as RAR $\beta$ and ER $\alpha$ in LNCaP-prostatospheroids, CAR $\alpha$ and DAX-1 in VCaP-prostatospheroids, PPARS and HNF4 $\alpha$ in DU145prostatospheroids), suggesting that these downregulated NRs in prostatospheroids might be involved in functions other than spheroid formation or they play other roles in the differentiated anchorage-dependent prostate cancer cells.

\section{Castration-resistant prostate cancer xenografts contain increased population of CD44+/CD133+ cell population}

Based on the post-castration-relapse growth of AR-positive VCaP cells toward androgen withdrawal, we established a xenograft model of castration-resistant prostate cancer VCaP-CRPC (Fig. 3A). It is also known that besides AR, dysregulation of signaling pathways mediated by other hormone NRs, such as GR and progesterone receptor (PR), is also implicated to be involved in the castration-resistant growth of prostate cancer (Latil et al. 2001, Montgomery et al. 2014). To investigate the growth status of PCSCs in the VCaP-CRPC xenografts in response to castration, we used the qRT-PCR to survey the expression patterns of PCSC markers by qRT-PCR and also their relative cell population by FACS. Results of qRT-PCR showed that there were significant increases of expressions of multiple PCSC markers at 4-day post-castration and relapse growth at 2-month post-castration, as compared to that at precastration (Fig. 3A). Results of FACS also confirmed that there was significant increase in population of $\mathrm{CD}_{4} 4^{+} / \mathrm{CD} 133^{+}$cells in VCaP-CRPC xenografts at 4-day post-castration (early response) and relapse growth at 2-month post-castration (late response) as compared to that at pre-castration (Fig. 3B). Immunofluorescence analysis also demonstrated that there was an increase in immunosignals of CD44 in VCaP-CRPC xenografts at 4-day post-castration and growth relapse at 2-month post-castration (Fig. 3C). Together, these results indicated that there was upregulation of PCSC-associated markers and also increase in population of PCSCs in the VCaPCRPC xenografts during their refractory growth in response to castration.

\section{VCaP-CRPC xenografts display distinct expression} profiles of NRs

To identify the NR members differentially expressed in the castration-refractory growth of VCaP-CRPC xenografts, we used the qRT-PCR to profile the temporal expression pattern of all NR members in VCaP-CRPC xenografts at early (4-day) and late (2-month) post-castration by qRT-PCR. Results revealed that almost half of the members of NR superfamily showed altered expressions in post-castrated VCaP-CRPC xenografts as compared to pre-castrated xenografts, with most of the identified NR members showing significant upregulation (Fig. 4A). Further analysis showed that 14 NRs, including 4 endocrine NRs (VDR, TR $\beta$, PR and MR), 4 adopted NRs (PPAR $\gamma$, CAR $\alpha$, FXR and RXR $\gamma$ ) and 6 orphan NRs (Rev-erb $\beta$, ROR $\beta$, TLX, COUP-TFII, NURR1 and LRH-1), were identified to express upregulation in VCaP-CRPC xenografts at both 4-day and 2-month post-castration (Fig. 4B). On the other hand, we detected only few NRs, which showed downregulation but with no consistent expression patterns, in the postcastrated VCaP-CRPC xenografts (Supplementary Fig. 3).

\section{Orphan NRs with common upregulation in prostatospheroids and castration-relapse VCaP-CRPC xenografts}

To identify the NR members that might play common roles in growth regulation of both prostatospheroids and VCaP-CRPC xenografts, we compared those NRs that show upregulation in both prostatospheroids and castration-relapse VCaP-CRPC xenografts. This pairwise comparison identified five orphan NRs (including ROR $\beta$, TLX, COUP-TFII, NURR1 and LRH-1), which showed common upregulation in both prostate cancer cell linesderived prostatospheroids and castration-relapse VCaPCRPC xenografts (Fig. 5A). qRT-PCR and immunoblot analyses re-confirmed that these orphan NRs displayed significant upregulation in both prostatospheroids and castration-relapse VCaP-CRPC xenografts (Fig. 5B and C). Together, our results suggested that the identified orphan NRs might play common roles in the growth regulation of PCSCs and also contribute to the castration-relapse of prostate cancer. 
A

\section{VCaP-CRPC model}

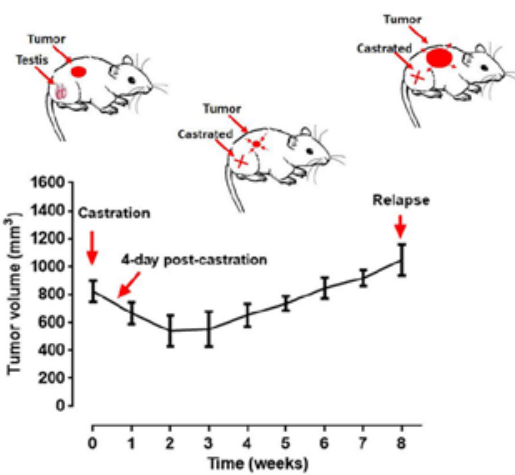

VCaP-CRPC model

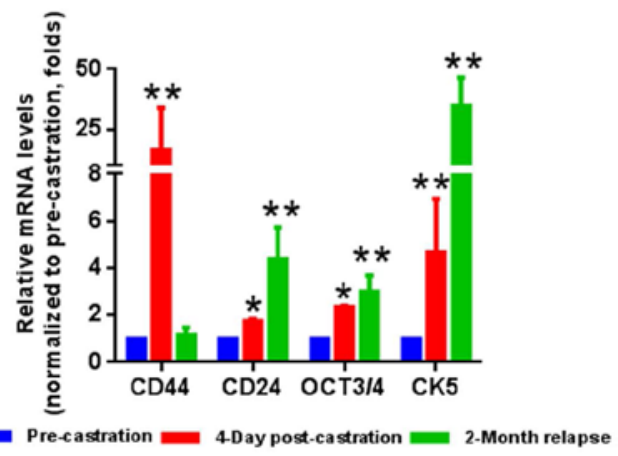

B
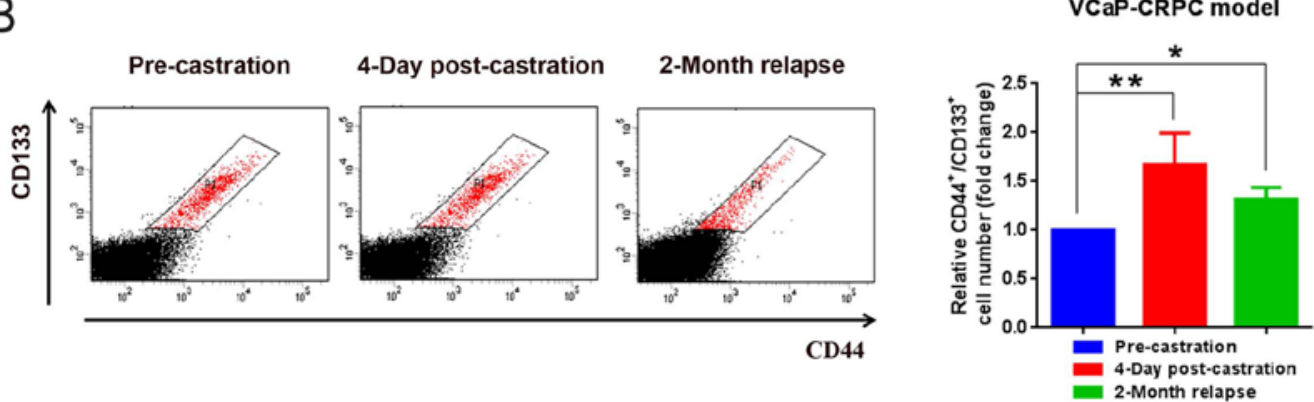

C

DAPI
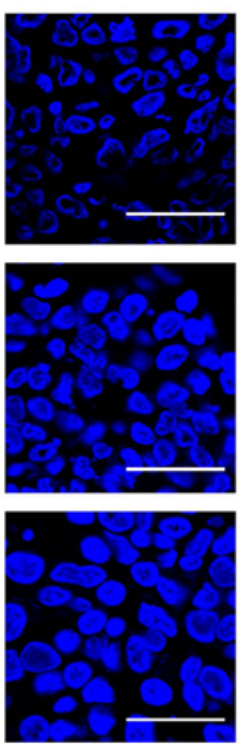

CD44
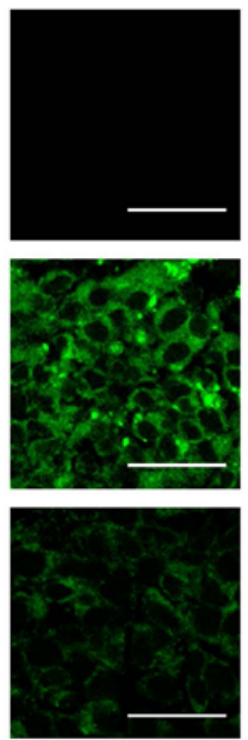
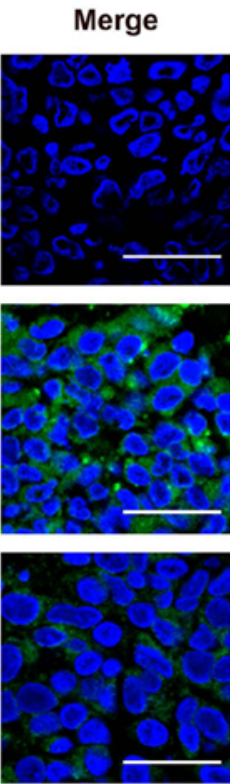

Pre-castration

4-Day

post-castration

2-Month relapse

Figure 3

Castration-relapse VCaP-CRPC xenografts contain more population of prostate cancer stem-like cells. (A) VCaP-CRPC xenografts were established based on the castration-relapse growth of VCaP xenografts in castrated host SCID mice $(n=5)$. Left: Growth curve of VCaP tumor xenografts in host mice during 0-8 weeks after castration. Relapse of tumor growth occurred at 4-week post-castration. Right: qRT-PCR analysis. Results showed that the VCaP-CRPC xenografts expressed significantly higher mRNA levels of several PCSC-associated markers (CD44, CD24, OCT3/4, and CK5). (B) FACS analysis. Results showed that VCaP-CRPC tumor xenografts harvested at 4-day and 2-month post-castration contained increased population of CD44+/CD133+ cells as compared to tumors harvested before castration. (C) CD44 immunofluorescence. Results showed that VCaP-CRPC tumor xenografts harvested at 4-day and 2-month post-castration expressed higher CD44 immunosignals at tumor cell membranes as compared to tumor cells harvested at pre-castration. Bars $=20 \mu \mathrm{m} . * P<0.05 ; * * P<0.01$ vs pre-castration. 
A 4-Day post-castration

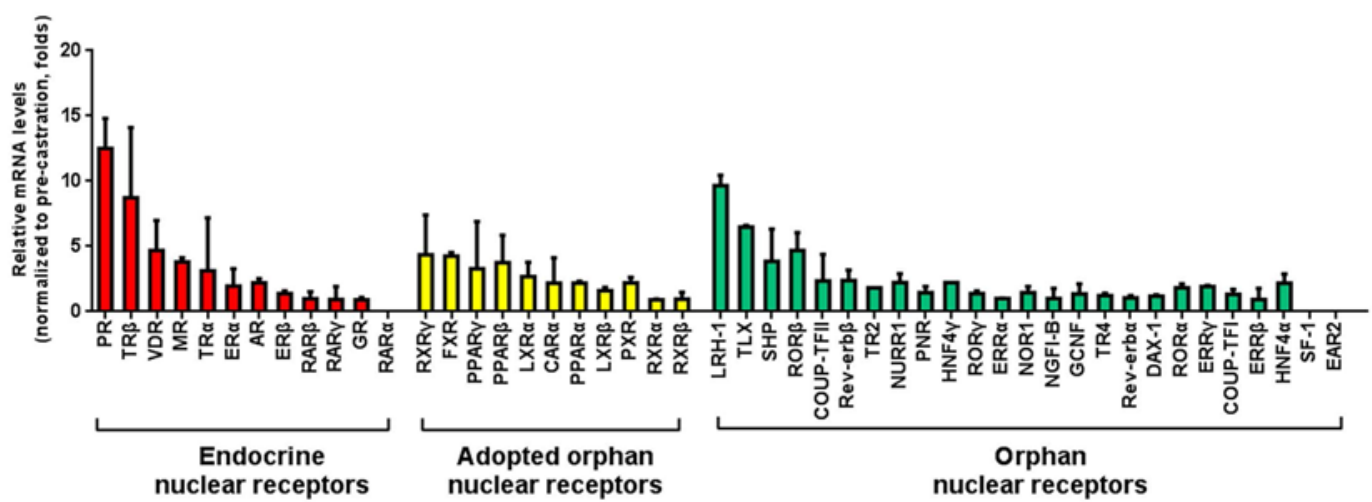

\section{2-Month relapse}

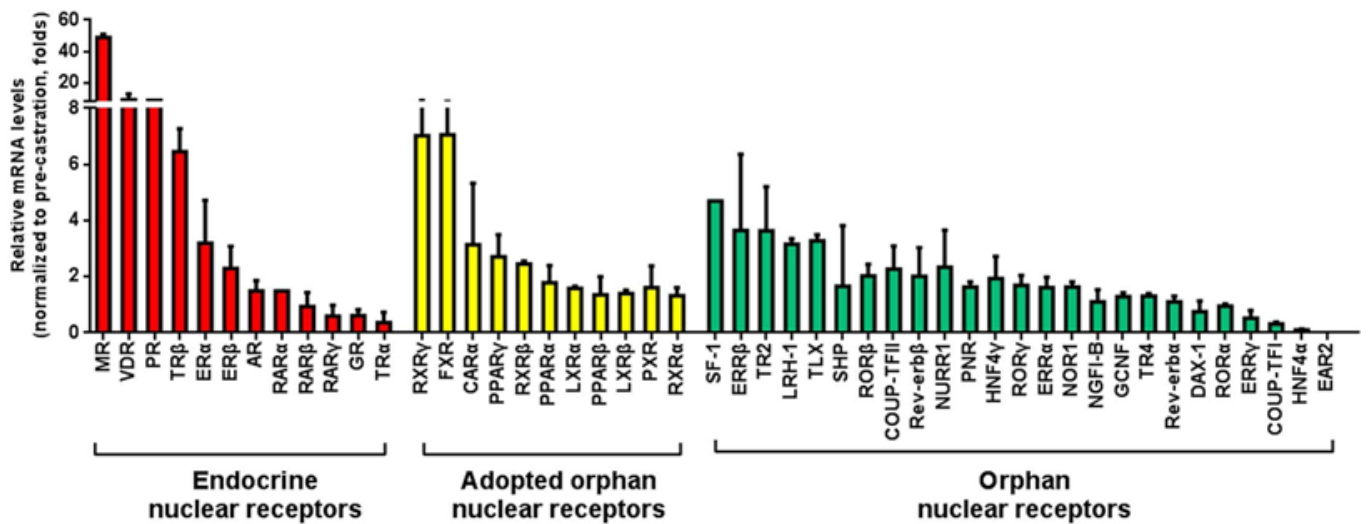

B

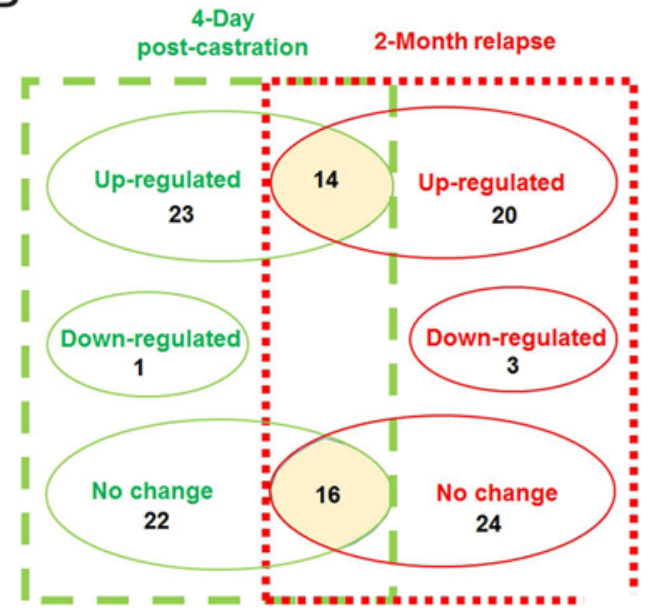

NRs up-regulated in the VCaP-CRPC model

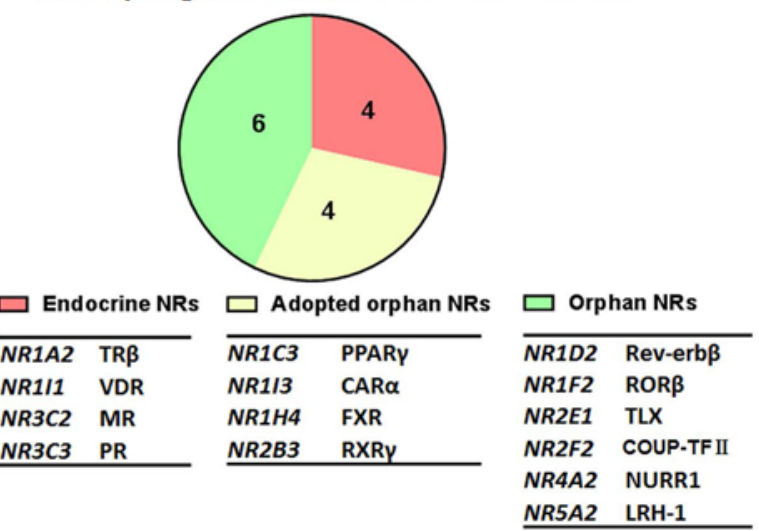

Figure 4

Castration-relapse VCaP-CRPC tumor xenografts display distinct expression profiles of NRs. (A and B) Histograms show the relative fold changes (RFC) of expression levels of NRs in VCaP-CRPC tumor xenografts harvested at 4-day and 2-month post-castration. Results revealed that over 20 NRs showing significant elevated expressions were identified in post-castrated VCaP-CRPC xenografts as compared to pre-castrated VCaP xenografts. (B) Left: data analysis showed that 14 NRs showing common upregulation were identified in VCaP-CRPC xenografts harvested at 4-day and 2-month post-castration. Right: a pie chart shows the NR numbers and a table shows the names of the identified upregulated NRs in the castration-relapse VCaP-CRPC tumor xenografts. 
A

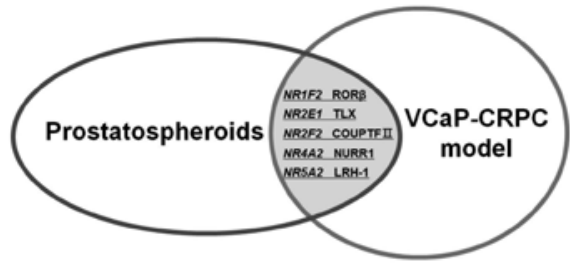

B

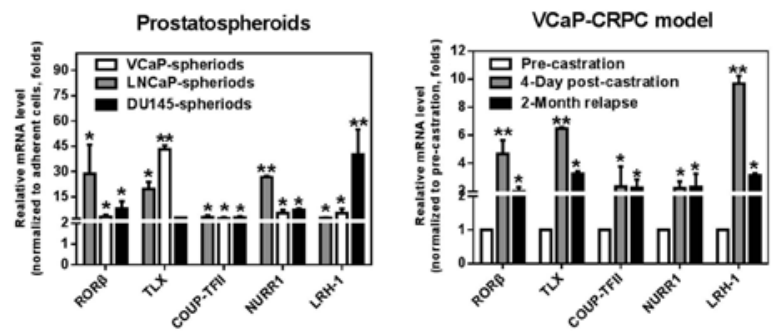

C
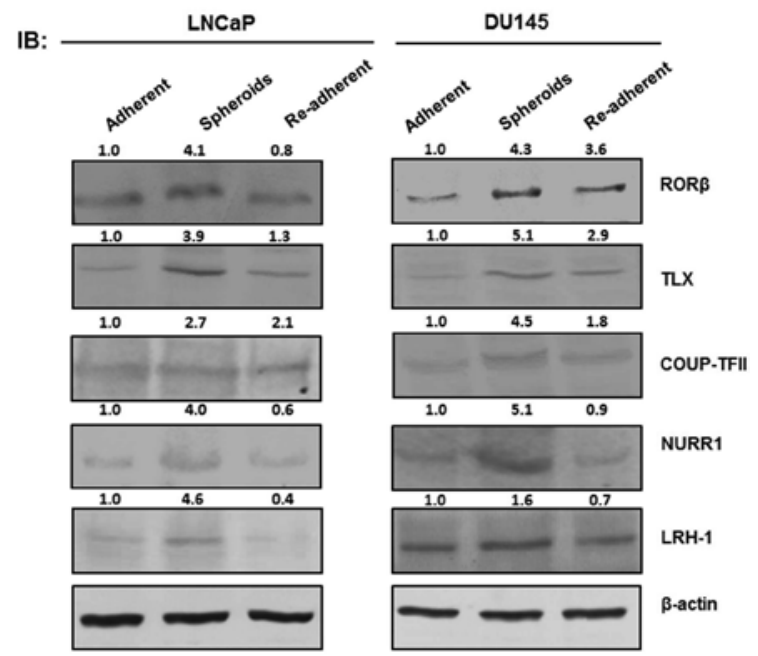

Figure 5

Expression analyses of NRs showing common upregulation in both prostate cancer cell line-derived prostatospheroids and post-castrated VCaP-CRPC tumor xenografts. (A) Five orphan NRs (including ROR $\beta$, TLX, COUP-TFII, NURR1 and LRH-1) were identified to exhibit common upregulation in both prostate cancer cell line-derived prostatospheroids and castration-relapse VCaP-CRPC tumor xenografts. (B) qRT-PCR analysis validated the common upregulation of the identified orphan NRs in prostatospheroids and post-castrated VCaP-CRPC tumor xenografts. * $P<0.05$; $* * P<0.01$ vs adherent parental cells or pre-castration. (C) Immunoblot analysis validated the elevated protein expressions of five identified orphan NRs (including ROR $\beta$, TLX, COUP-TFII, NURR1 and LRH-1) in LNCaP- and DU145-derived prostatospheroids, and VCaP-CRPC xenograft model. Their expressions became reduced in prostatospheroid-derived re-adherent cells cultured under 2D culture condition. Similar to LNCaP/DU145-derived prostatospheroids, increased protein expressions of five orphan NRs were shown in 2-month post-castration VCaP-CRPC tumors. Representative figures shown above the blots represent the $\beta$-actin normalized levels relative to either adherent cells grown under 2D culture condition or pre-castration VCaP xenograft tumors.

Identified orphan NRs show upregulation in abirateronetreated VCaP-CRPC xenografts and FACS-sorted CD133+primary prostate cancer cells

To further provide an insight into the identified orphan NRs in CRPC progression and PCSCs, we next examined their mRNA expressions in VCaP-CRPC xenografts upon abiraterone treatment and FACS-sorted CD133+-primary prostate cancer cells isolated from clinical samples. Results showed that all the five orphan NRs exhibited increased expressions in the abiraterone-treated VCaPCRPC xenografts and three of these NRs (TLX, NURR1 and LRH-1) displayed upregulation in FACS-sorted CD133+-primary prostate cancer cells (Fig. 6A and B). Moreover, using several publically available oncogenomic datasets of prostate cancer (Magee et al. 2001, Vanaja et al. 2003, Yu et al. 2004, Liu et al. 2006, Tomlins et al. 2007, Arredouani et al. 2009, Taylor et al. 2010, Grasso et al. 2012), we also validated that all the five orphan NRs showed increased expressions in clinical prostate cancer samples as compared to normal prostate gland (Fig. 6C). Our results further validated the upregulation patterns of the five orphan NRs in prostate cancer, and suggest that these NRs may play critical roles in prostate cancer and also PCSCs.
Overexpressions of five identified orphan NRs promote spheroid formation capacity of prostate cancer cells

Based on their common upregulation in both prostatospheroids and castration-relapse VCaP-CRPC xenograft tumors, we hypothesize that the identified orphan NRs might play positive roles in the advanced growth of prostate cancer, particularly the CRPC contributed by PCSCs. We then generated orphan NR infectants (including ROR $\beta$, TLX, COUP-TFII, NURR1 and LRH-1) in LNCaP and DU145 cells in order to evaluate the functional significances of these orphan NRs in prostate cancer growth. All the immunoblotvalidated infectants displayed increased expressions of multiple PCSC-associated markers, among which CD44, CD133 and CK14 showed common upregulation in all generated infectants (Fig. 7A and $\mathrm{B}$ ). In vitro sphere formation assay showed that all orphan NR infectants exhibited significant enhanced sphere formation capacity (cancer stem-like cell phenotype) as compared to respective vector infectants (Fig. 7C). Together, these results suggested that the five identified orphan NRs could perform common positive roles in the growth promotion of PCSCs regardless of their AR expression status. 
A

VCaP-CRPC model upon abiraterone treatment
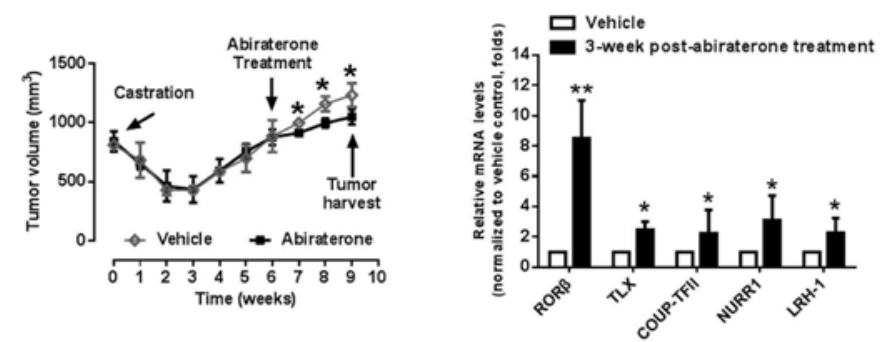

B
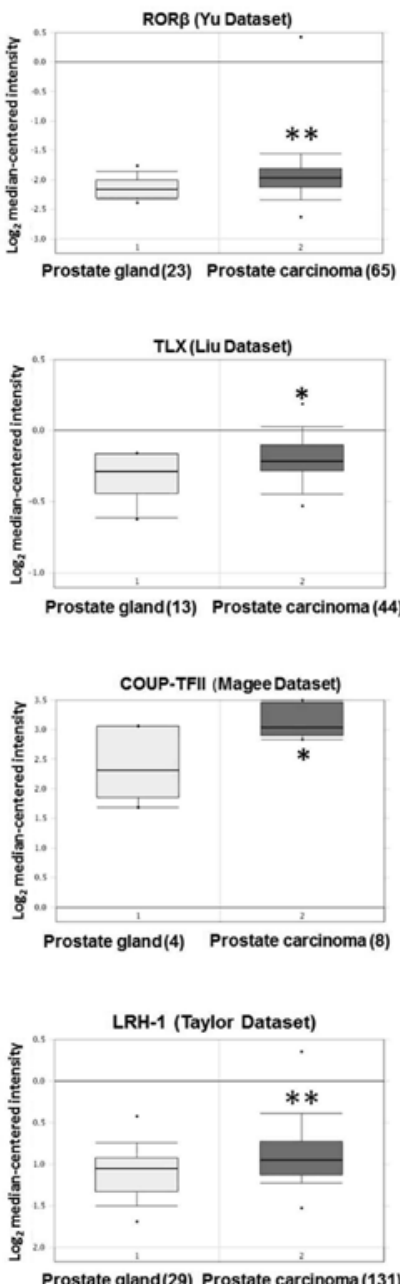
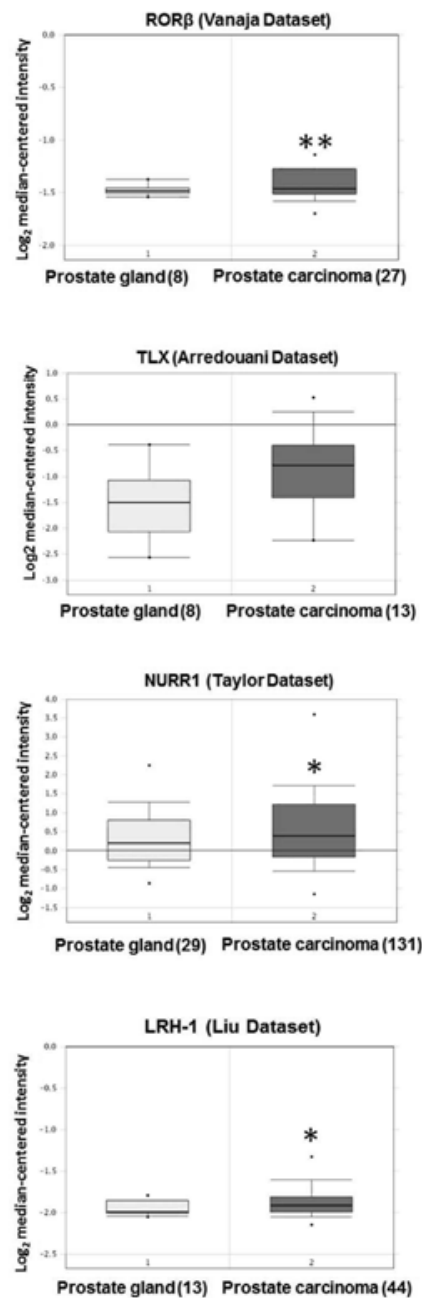
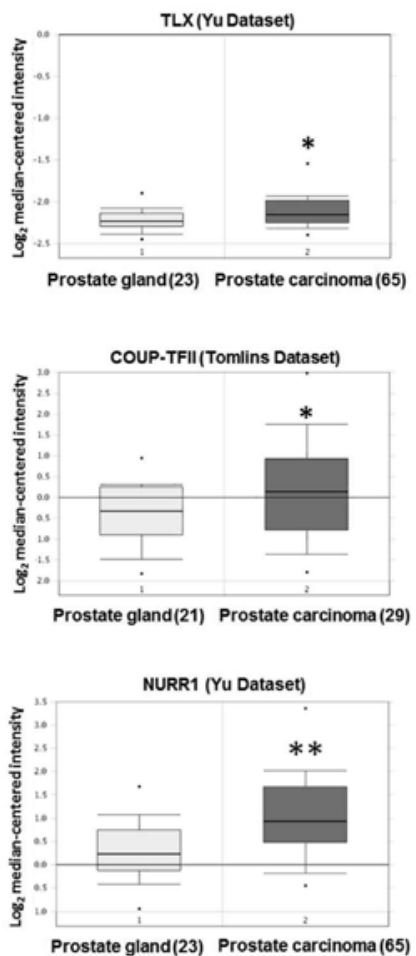

FACS-sorted CD133 ${ }^{+}$-primary prostate cancer cells

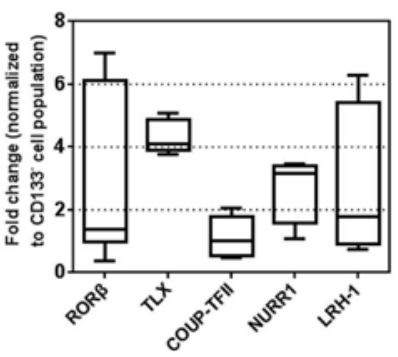

Prostate gland(23) Prostate carcinoma (65)

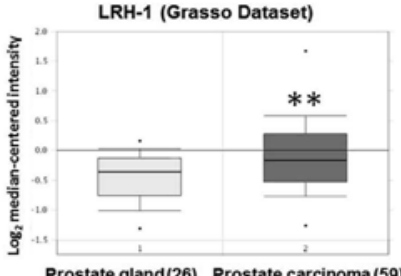

Figure 6

Upregulation of five identified orphan NRs shown in abiraterone-treated VCaP-CRPC xenografts, FACS-sorted CD133+-primary prostate cancer cells and clinical prostate cancer samples. (A) Abiraterone treatment of castration-relapse VCaP-CRPC xenograft model. qRT-PCR results showed that the abiraterone-treated VCaP-CRPC tumors expressed higher levels of the five identified orphan NRs (ROR $\beta$, TLX, COUP-TFII, NURR1 and LRH-1) as compared to vehicle-treated tumors. ${ }^{*} P<0.05 ; * *<0.01$ vs vehicle treatment. (B) FACS-sorted CD133+-primary prostate cancer cells. qRT-PCR results showed that the FACS-sorted CD133+-primary prostate cancer cells showed higher levels of TLX, NURR1 and LRH-1 as compared to CD133- cells. (C) Oncogenomic analysis of the five identified orphan NRs in prostate cancer clinical samples using the ONCOMINE datasets (http://www.oncomine.org). Results of expressions showed that higher log 2 median-centered intensities of ROR $\beta$, TLX, COUP-TFII, NURR1 and LRH-1 were detected in clinical prostate cancer samples as compared to normal prostate gland tissues. Individual data points are presented as means ( \pm S.E.M.) by boxplots of the log 2 median-centered intensity where the greater intensity indicates greater gene expression. ${ }^{*} P<0.05 ;{ }^{*} P<0.01$ prostate carcinoma vs normal prostate. 
A

IB:
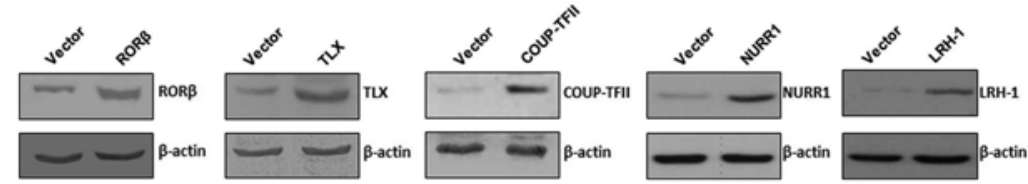

B
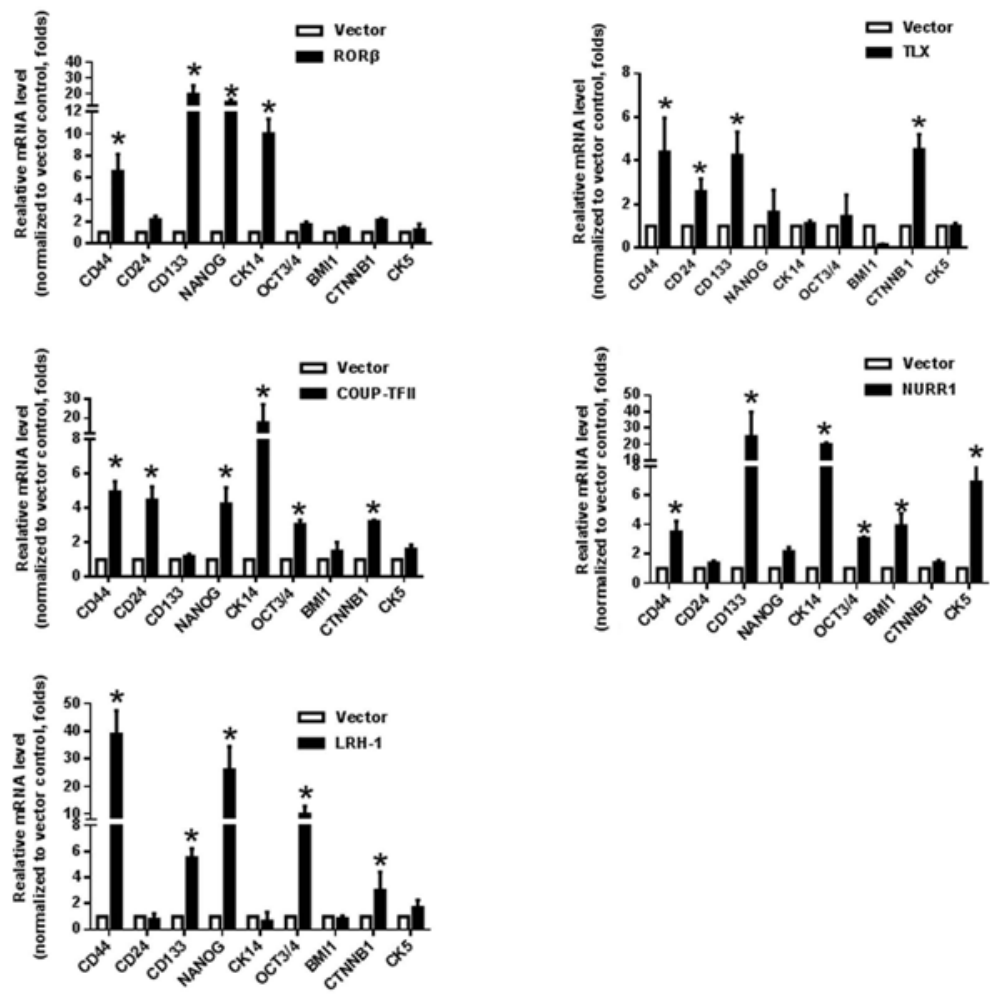

C
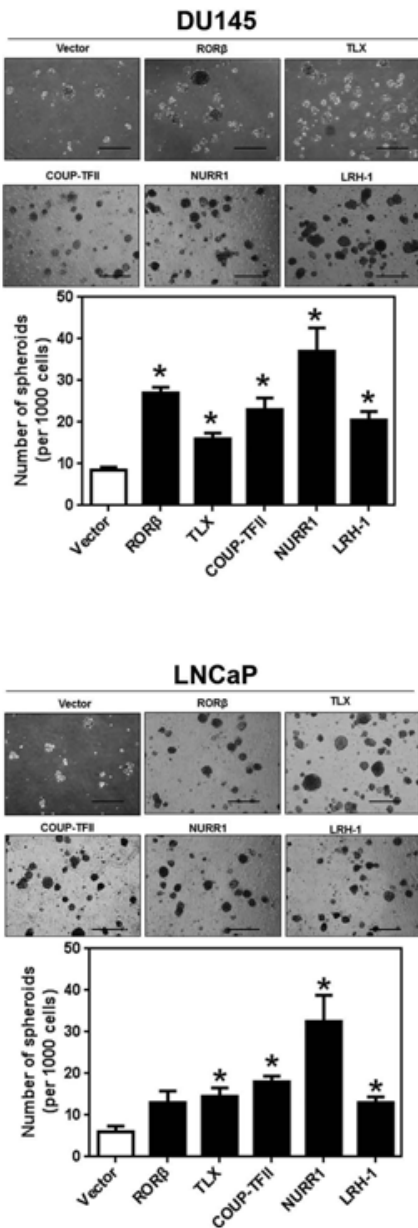

Figure 7

Stable prostate cancer infectants with overexpression of the five identified orphan NRs show increased expression of PCSC-associated markers and enhanced sphere formation capacity. (A) Immunoblot validation of DU145 infectants with stable overexpression of five respective orphan NRs (ROR $\beta$, TLX, COUP-TFII, NURR1 and LRH-1). (B) All five validated DU145 infectants showed increased expressions of multiple PCSC-associated markers as compared to their vector infectants. ${ }^{*} P<0.05$ vs vector infectants. (C) Upper panels: representative images of $3 \mathrm{D}$-cultured prostatospheroids formed by the orphan NR or vector infectants of DU145 and LNCaP cells. Lower panels: Quantitative analysis of prostatospheroids formed by the respective infectants. All five orphan NR infectants of DU145 and LNCaP cells showed significant enhanced sphere formation capacity than their respective vector infectants. ${ }^{*} P<0.05$ vs vector infectants.

\section{Discussion}

In this study, we employed the real-time qRT-PCR to survey and compare the expression profiles of members of the entire NR superfamily in PCSC-enriched prostatospheroids grown under the non-adherent 3D-culture condition and the castration-relapse VCaP-CRPC tumor xenografts in order to identify the differentially expressed NRs in these prostate cancer models. Our findings revealed that both the 3D-cultured prostatospheroids and postcastrated VCaP-CRPC xenografts exhibited distinct expression profiles of NRs and also identified five orphan NRs that showed common upregulation pattern in both prostatospheroids and VCaP-CRPC tumor xenografts. Importantly, ectopic overexpression of these orphan NRs could increase expressions of some PCSC-associated markers and enhance the sphere formation capacity (stemness) in prostate cancer cells. The results suggested that the identified orphan NRs might perform certain roles in the regulation of PCSCs and also serve as potential biomarkers or therapeutic targets for CRPC.

Here, we identified a total of 21 NRs, showing common upregulation in PCSC-enriched prostatospheroids derived from three prostate cancer cell lines regardless of their AR expression status, many of which belong to the orphan NRs and have not been known or functionally characterized 
previously in prostate cancer or PCSCs. Their common expression patterns also suggest that these NRs may play positive roles in the growth and maintenance of PCSCs, as both prostatospheroids and castration-relapse VCaPCRPC xenografts contain increased population of PCSCs. Using a similar methodology, Xie et al. (2009) previously reported the expression profile of NR superfamily in both human and mouse embryonic stem cell lines. Comparing their dataset and ours, it is noted that 10 NRs (including GR, MR, RXR $\alpha$, Rev-erb $\alpha$, ROR $\alpha$, TR4, COUP-TFI, COUPTFII, NURR1 and LRH-1) show common expressions in both human embryonic stems and PCSCs, suggesting that these NRs may play common roles in the growth regulation of embryonic stem cells and PCSCs. Indeed, a few of these orphan NRs have been described to be associated with PCSCs or androgen-independent prostate cancer cells. TR4 (NR2C2) is shown to be highly expressed in the CD133+-stem-like cell population derived from the androgen-insensitive and bone-metastatic prostate cancer cell line C4-2 and functionally associated with the chemoresistance of prostate cancer cells via the Oct4-IL-1 receptor signaling axis (Yang et al. 2013). COUP-TFI (NR2F1) is also demonstrated to be upregulated in circulating or disseminated tumor cells from prostate cancer patients carrying dormant disease and COUP-TFImediated signaling is characterized to be responsible for the control of quiescence or dormancy of prostate cancer cells in bone marrow via its regulation of targets SOX9 and RAR $\beta$, and global chromatin repression (Sosa et al. 2015). Similarly, we also identified 14 NRs, all of which have not been demonstrated previously to be expressed or associated with CRPC, showing upregulation in both short- and long-term post-castrated VCaP-CRPC xenografts. We have previously shown that PR (NR3C3) transcripts are detected in a few AR-positive prostate cancer cell lines (LNCaP, C4-2B) but not in immortalized prostatic epithelial cell lines (Cheung et al. 2005).

Here, we demonstrated that both 3D-cultured prostatospheroids derived from either AR-positive or -negative prostate cancer cell lines and post-castrated VCaP-CRPC xenografts contained increased population of PCSCs. These results agree with the current notion that PCSCs play important roles not only in the tumor initiation but also the advanced growth of metastatic CRPC (Kerr \& Hussain 2014). The PCSC-conferred castration or therapy resistance involves multiple pathways, including dysregulation of AR and androgen metabolism, aberrant or activated signaling pathways regulated by growth factor receptor tyrosine kinases and cytokines
(PI3K-AKT, RAS-MAPK, STAT3), PTEN, Wnt, Notch and hedgehog ( $\mathrm{Ni}$ et al. 2014, Rybak et al. 2015). Pairwise analysis identified five orphan NRs, namely $\operatorname{ROR} \beta$, TLX, COUP-TFII, NURR1 and LRH-1, which showed common upregulation in both prostatospheroids and postcastrated VCaP-CRPC xenografts. We also examined the expression patterns of the five orphan NRs in a CRPCderived AR-positive cell line 22Rv1 and charcoal-stripped serum (CSS)-treated VCaP cells. Our results validated that all five orphan NRs showed increased expressions in 22Rv1-derived prostatospheroids (Supplementary Fig. 4A, $\mathrm{B}$ and C) and CSS-treated VCaP cells (Supplementary Fig. 4D). Moreover, we also showed that all five orphan NRs exhibited increased expressions in the castrationrefractory VCaP-CRPC xenograft model upon abiraterone treatment at the tumor relapse stage, suggesting that these orphan NRs may play roles in the abiraterone resistance in CRPC. Some of these identified orphan NRs (including TLX, LRH-1 and NURR1) also displayed upregulation in FACS-sorted CD133+-primary cultured prostate cancer cells isolated from clinical prostate cancer specimens. However, the specific roles or signaling pathways mediated by these orphan NRs in PCSCs or CRPC are yet to be defined and need further exploration. Recently, we have demonstrated that TLX (NR2E1), which exhibits an upregulated expression in prostate cancer tissues with high Gleason score, can function as a potent suppressor of oncogene-induced senescence in prostate cancer cells via its transcriptional co-regulation of two senescence-associated genes CDKN1A (p21) and SIRT1 (Wu et al. 2015). COUP-TFII (NR2F2), of which increased expression is positively correlated with the aggressiveness and recurrence of prostate cancer, can repress the AR transactivation in LNCaP prostate cancer cells and function to promote the Pten-null-mediated prostate tumorigenesis via its inhibition of TGF- $\beta$ signaling as demonstrated in transgenic mouse studies (Song et al. 2012, Qin et al. 2013). Transient knockdown of NURR1 (NR4A2), which also displays increased expression in high Gleason score prostate cancer, can suppress the in vitro cell proliferation and migration of PC-3 prostate cancer cells (Wang et al. 2013).

In summary, our findings not only reveal the expression patterns of the entire NR superfamily in 3D prostatospheroids and castration-resistant VCaP-CRPC xenograft model but also provide an insight into that some of the identified orphan NRs with common upregulations in these models could be useful as markers or potential therapeutic targets common for both the PCSCs and the therapy-resistant CRPC. 


\section{Supplementary data}

This is linked to the online version of the paper at $h t t p: / / d x . d o i . o r g / 10.1530 /$ ERC-17-0280

\section{Declaration of interest}

The authors declare that there is no conflict of interest that could be perceived as prejudicing the impartiality of the research reported.

\section{Funding}

This work was supported by grants from the Hong Kong Research Grants Council (General Research Fund GRF, project numbers 14100914 and 14107116), Food and Health Bureau (Health and Medical Research Fund HMRF, grant number 02130066), CUHK (Direct Grant for Research, 2012.1.055) and National Natural Science Foundation of China (81502570).

\section{Author contribution statement}

ZW performed the experiments and drafted the manuscript. D W performed the 3D cultures, flow cytometric analysis and immunofluorescence. $Y \mathrm{~W}$ performed the animal experiments. C F N and J Y C T provided clinical samples and interpreted results. $S Y, Y$ W and $F L C$ conceived the study and its design, obtained fundings for the study, drafted and revised the manuscript. All authors read and approved the final manuscript.

\section{References}

Agoulnik IU, Krause WC, Bingman WE 3rd, Rahman HT, Amrikachi M, Ayala GE \& Weigel NL 2003 Repressors of androgen and progesterone receptor action. Journal of Biological Chemistry 278 31136-31148. (https://doi.org/10.1074/jbc.M305153200)

Ahn J, Park S, Zuniga B, Bera A, Song CS \& Chatterjee B 2016 Vitamin D in prostate cancer. Vitamins and Hormones 100 321-355. (https://doi. org/10.1016/bs.vh.2015.10.012)

Antonarakis ES, Lu C, Wang H, Luber B, Nakazawa M, Roeser JC, Chen Y, Mohammad TA, Chen Y, Fedor HL, et al. 2014 AR-V7 and resistance to enzalutamide and abiraterone in prostate cancer. New England Journal of Medicine 371 1028-1038. (https://doi.org/10.1056/ NEJMoa1315815

Arredouani MS, Lu B, Bhasin M, Eljanne M, Yue W, Mosquera JM, Bubley GJ, Li V, Rubin MA, Libermann TA, et al. 2009 Identification of the transcription factor single-minded homologue 2 as a potential biomarker and immunotherapy target in prostate cancer. Clinical Cancer Research 15 5794-5802. (https://doi.org/10.1158/1078-0432. CCR-09-0911)

Ben-Eltriki M, Deb S \& Guns ES 2016 Calcitriol in combination therapy for prostate cancer: pharmacokinetic and pharmacodynamic interactions. Journal of Cancer 7 391-407. (https://doi.org/10.7150/ jca.13470)

Bookout AL, Jeong Y, Downes M, Yu RT, Evans RM \& Mangelsdorf DJ 2006 Anatomical profiling of nuclear receptor expression reveals a hierarchical transcriptional network. Cell 126 789-799. (https://doi. org/10.1016/j.cell.2006.06.049)

Chawla A, Repa JJ, Evans RM \& Mangelsdorf DJ 2001 Nuclear receptors and lipid physiology: opening the X-files. Science 294 1866-1870. (https://doi.org/10.1126/science.294.5548.1866)

Cheung CP, Yu S, Wong KB, Chan LW, Lai FM, Wang X, Suetsugi M, Chen S \& Chan FL 2005 Expression and functional study of estrogen receptor-related receptors in human prostatic cells and tissues.
Journal of Clinical Endocrinology and Metabolism 90 1830-1844. (https://doi.org/10.1210/jc.2004-1421)

Grasso CS, Wu YM, Robinson DR, Cao X, Dhanasekaran SM, Khan AP, Quist MJ, Jing X, Lonigro RJ, Brenner JC, et al. 2012 The mutational landscape of lethal castration-resistant prostate cancer. Nature $\mathbf{4 8 7}$ 239-243. (https://doi.org/10.1038/nature11125)

Huggins C \& Hodges CV 1941 Studies on prostatic cancer. I. The effect of castration, of estrogen and androgen injection on serum phosphatases in metastatic carcinoma of the prostate. CA: A Cancer Journal for Clinicians 22 232-240. (https://doi.org/10.3322/ canjclin.22.4.232)

Jeong Y \& Mangelsdorf DJ 2009 Nuclear receptor regulation of stemness and stem cell differentiation. Experimental and Molecular Medicine 41 525-537. (https://doi.org/10.3858/emm.2009.41.8.091)

Jeong Y, Xie Y, Xiao G, Behrens C, Girard L, Wistuba, II, Minna JD \& Mangelsdorf DJ 2010 Nuclear receptor expression defines a set of prognostic biomarkers for lung cancer. PLoS Medicine 7 e1000378. (https://doi.org/10.1371/journal.pmed.1000378)

Jeong Y, Xie Y, Lee W, Bookout AL, Girard L, Raso G, Behrens C, Wistuba, II, Gadzar AF, Minna JD, et al. 2012 Research resource: diagnostic and therapeutic potential of nuclear receptor expression in lung cancer. Molecular Endocrinology 26 1443-1454. (https://doi. org/10.1210/me.2011-1382)

Kach J, Conzen SD \& Szmulewitz RZ 2015 Targeting the glucocorticoid receptor in breast and prostate cancers. Science Translational Medicine 7 305ps319. (https://doi.org/10.1126/scitranslmed.aac7531)

Karantanos T, Evans CP, Tombal B, Thompson TC, Montironi R \& Isaacs WB 2015 Understanding the mechanisms of androgen deprivation resistance in prostate cancer at the molecular level. European Urology 67 470-479. (https://doi.org/10.1016/j. eururo.2014.09.049)

Kerr CL \& Hussain A 2014 Regulators of prostate cancer stem cells. Current Opinion in Oncology 26 328-333. (https://doi.org/10.1097/ CCO.0000000000000080)

Knower KC, Chand AL, Eriksson N, Takagi K, Miki Y, Sasano H, Visvader JE, Lindeman GJ, Funder JW, Fuller PJ, et al. 2013 Distinct nuclear receptor expression in stroma adjacent to breast tumors. Breast Cancer Research and Treatment 142 211-223. (https://doi. org/10.1007/s10549-013-2716-6)

Lahnalampi M, Heinaniemi M, Sinkkonen L, Wabitsch M \& Carlberg C 2010 Time-resolved expression profiling of the nuclear receptor superfamily in human adipogenesis. PLoS ONE 5 e12991. (https://doi.org/10.1371/journal.pone.0012991)

Lallous N, Volik SV, Awrey S, Leblanc E, Tse R, Murillo J, Singh K, Azad AA, Wyatt AW, LeBihan S, et al. 2016 Functional analysis of androgen receptor mutations that confer anti-androgen resistance identified in circulating cell-free DNA from prostate cancer patients. Genome Biology 17 10. (https://doi.org/10.1186/s13059-015-0864-1)

Latil AG, Azzouzi R, Cancel GS, Guillaume EC, Cochan-Priollet B, Berthon PL \& Cussenot O 2001 Prostate carcinoma risk and allelic variants of genes involved in androgen biosynthesis and metabolism pathways. Cancer 92 1130-1137. (https://doi.org/10.1002/10970142(20010901)92:5<1130::AID-CNCR1430>3.0.CO;2-B)

Li H, Jiang M, Honorio S, Patrawala L, Jeter CR, Calhoun-Davis T, Hayward SW \& Tang DG 2009 Methodologies in assaying prostate cancer stem cells. Methods in Molecular Biology 568 85-138. (https://doi.org/10.1007/978-1-59745-280-9_7)

Lin SJ, Yang DR, Li G \& Chang C 2015 TR4 nuclear receptor different roles in prostate cancer progression. Frontiers in Endocrinology 678. (https://doi.org/10.3389/fendo.2015.00078)

Liu P, Ramachandran S, Ali Seyed M, Scharer CD, Laycock N, Dalton WB, Williams H, Karanam S, Datta MW, Jaye DL, et al. 2006 Sex-determining region $\mathrm{Y}$ box 4 is a transforming oncogene in human prostate cancer cells. Cancer Research 66 4011-4019. (https://doi.org/10.1158/0008-5472.CAN-05-3055) 
Lukacs RU, Goldstein AS, Lawson DA, Cheng D \& Witte ON 2010 Isolation, cultivation and characterization of adult murine prostate stem cells. Nature Protocols 5 702-713. (https://doi.org/10.1038/ nprot.2010.11)

Magee JA, Araki T, Patil S, Ehrig T, True L, Humphrey PA, Catalona WJ, Watson MA \& Milbrandt J 2001 Expression profiling reveals hepsin overexpression in prostate cancer. Cancer Research 61 5692-5696.

Modica S, Gofflot F, Murzilli S, D'Orazio A, Salvatore L, Pellegrini F, Nicolucci A, Tognoni G, Copetti M, Valanzano R, et al. 2009 The intestinal nuclear receptor signature with epithelial localization patterns and expression modulation in tumors. Gastroenterology 138 636-648, 648.e601-648.e612. (https://doi.org/10.1053/j. gastro.2009.09.060)

Montgomery B, Cheng HH, Drechsler J \& Mostaghel EA 2014 Glucocorticoids and prostate cancer treatment: friend or foe? Asian Journal of Andrology 16 354-358. (https://doi.org/10.4103/1008682X.125392)

Moya M, Gomez-Lechon MJ, Castell JV \& Jover R 2010 Enhanced steatosis by nuclear receptor ligands: a study in cultured human hepatocytes and hepatoma cells with a characterized nuclear receptor expression profile. Chemico-Biological Interactions 184 376-387. (https://doi.org/10.1016/j.cbi.2010.01.008)

Mu X \& Chang C 2003 TR2 orphan receptor functions as negative modulator for androgen receptor in prostate cancer cells PC-3. Prostate 57 129-133. (https://doi.org/10.1002/pros.10282)

Ni J, Cozzi P, Hao J, Duan W, Graham P, Kearsley J \& Li Y 2014 Cancer stem cells in prostate cancer chemoresistance. Current Cancer Drug Targets 14 225-240. (https://doi.org/10.2174/1568009614666140328 152459)

Nishimura M, Naito S \& Yokoi T 2004 Tissue-specific mRNA expression profiles of human nuclear receptor subfamilies. Drug Metabolism and Pharmacokinetics 19 135-149. (https://doi.org/10.2133/dmpk.19.135)

Pastrana E, Silva-Vargas V \& Doetsch F 2011 Eyes wide open: a critical review of sphere-formation as an assay for stem cells. Cell Stem Cell $\mathbf{8}$ 486-498. (https://doi.org/10.1016/j.stem.2011.04.007)

Qin J, Wu SP, Creighton CJ, Dai F, Xie X, Cheng CM, Frolov A, Ayala G, Lin X, Feng XH, et al. 2013 COUP-TFII inhibits TGF-beta-induced growth barrier to promote prostate tumorigenesis. Nature 493 236-240. (https://doi.org/10.1038/nature11674)

Ryan CJ, Smith MR, Fizazi K, Saad F, Mulders PF, Sternberg CN, Miller K, Logothetis CJ, Shore ND, Small EJ, et al. 2015 Abiraterone acetate plus prednisone versus placebo plus prednisone in chemotherapynaive men with metastatic castration-resistant prostate cancer (COU-AA-302): final overall survival analysis of a randomised, double-blind, placebo-controlled phase 3 study. Lancet Oncology 16 152-160. (https://doi.org/10.1016/S1470-2045(14)71205-7)

Rybak AP, Bristow RG \& Kapoor A 2015 Prostate cancer stem cells: deciphering the origins and pathways involved in prostate tumorigenesis and aggression. Oncotarget 6 1900-1919. (https://doi. org/10.18632/oncotarget.2953)

Sahu B, Laakso M, Pihlajamaa P, Ovaska K, Sinielnikov I, Hautaniemi S \& Janne OA 2013 FoxA1 specifies unique androgen and glucocorticoid receptor binding events in prostate cancer cells. Cancer Research 73 1570-1580. (https://doi.org/10.1158/0008-5472. CAN-12-2350)

Schote AB, Turner JD, Schiltz J \& Muller CP 2007 Nuclear receptors in human immune cells: expression and correlations. Molecular Immunology 44 1436-1445. (https://doi.org/10.1016/j. molimm.2006.04.021)

Song CH, Lee HJ, Park E \& Lee K 2012 The chicken ovalbumin upstream promoter-transcription factor II negatively regulates the transactivation of androgen receptor in prostate cancer cells. PLoS ONE 7 e49026. (https://doi.org/10.1371/journal.pone.0049026)

Sosa MS, Parikh F, Maia AG, Estrada Y, Bosch A, Bragado P, Ekpin E, George A, Zheng Y, Lam HM, et al. 2015 NR2F1 controls tumour cell dormancy via SOX9- and RARbeta-driven quiescence programmes.
Nature Communications 6 6170. (https://doi.org/10.1038/ ncomms7170)

Steinestel J, Luedeke M, Arndt A, Schnoeller TJ, Lennerz JK, Wurm C, Maier C, Cronauer MV, Steinestel K \& Schrader AJ 2015 Detecting predictive androgen receptor modifications in circulating prostate cancer cells. Oncotarget [epub]. (https://doi.org/10.18632/ oncotarget.3925)

Taylor BS, Schultz N, Hieronymus H, Gopalan A, Xiao Y, Carver BS, Arora VK, Kaushik P, Cerami E, Reva B, et al. 2010 Integrative genomic profiling of human prostate cancer. Cancer Cell 18 11-22. (https://doi.org/10.1016/j.ccr.2010.05.026)

Tomlins SA, Mehra R, Rhodes DR, Cao X, Wang L, Dhanasekaran SM, Kalyana-Sundaram S, Wei JT, Rubin MA, Pienta KJ, et al. 2007 Integrative molecular concept modeling of prostate cancer progression. Nature Genetics 39 41-51. (https://doi.org/10.1038/ ng1935)

Vanaja DK, Cheville JC, Iturria SJ \& Young CY 2003 Transcriptional silencing of zinc finger protein 185 identified by expression profiling is associated with prostate cancer progression. Cancer Research 63 3877-3882.

Wang J, Yang J, Zou Y, Huang GL \& He ZW 2013 Orphan nuclear receptor nurr1 as a potential novel marker for progression in human prostate cancer. Asian Pacific Journal of Cancer Prevention 14 2023-2028. (https://doi.org/10.7314/APJCP.2013.14.3.2023)

Wang J, Zou JX, Xue X, Cai D, Zhang Y, Duan Z, Xiang Q, Yang JC, Louie MC, Borowsky AD, et al. 2016 ROR-gamma drives androgen receptor expression and represents a therapeutic target in castrationresistant prostate cancer. Nature Medicine 22 488-496. (https://doi. org/10.1038/nm.4070)

Wu D, Yu S, Jia L, Zou C, Xu Z, Xiao L, Wong KB, Ng CF \& Chan FL 2015 Orphan nuclear receptor TLX functions as a potent suppressor of oncogene-induced senescence in prostate cancer via its transcriptional co-regulation of the CDKN1A (p21(WAF1) (/) (CIP1)) and SIRT1 genes. Journal of Pathology 236 103-115. (https://doi. org/10.1002/path.4505)

Xie CQ, Jeong Y, Fu M, Bookout AL, Garcia-Barrio MT, Sun T, Kim BH, Xie Y, Root S, Zhang J, et al. 2009 Expression profiling of nuclear receptors in human and mouse embryonic stem cells. Molecular Endocrinology 23 724-733. (https://doi.org/10.1210/me.2008-0465)

Yang DR, Ding XF, Luo J, Shan YX, Wang R, Lin SJ, Li G, Huang CK, Zhu J, Chen Y, et al. 2013 Increased chemosensitivity via targeting testicular nuclear receptor 4 (TR4)-Oct4-interleukin 1 receptor antagonist (IL1Ra) axis in prostate cancer CD133+ stem/progenitor cells to battle prostate cancer. Journal of Biological Chemistry $\mathbf{2 8 8}$ 16476-16483. (https://doi.org/10.1074/jbc.M112.448142)

Yu YP, Landsittel D, Jing L, Nelson J, Ren B, Liu L, McDonald C, Thomas R, Dhir R, Finkelstein S, et al. 2004 Gene expression alterations in prostate cancer predicting tumor aggression and preceding development of malignancy. Journal of Clinical Oncology 22 2790-2799. (https://doi.org/10.1200/JCO.2004.05.158)

Yu S, Wang X, Ng CF, Chen S \& Chan FL 2007 ERRgamma suppresses cell proliferation and tumor growth of androgen-sensitive and androgen-insensitive prostate cancer cells and its implication as a therapeutic target for prostate cancer. Cancer Research 67 4904-4914. (https://doi.org/10.1158/0008-5472.CAN-06-3855)

Yu S, Wong YC, Wang XH, Ling MT, Ng CF, Chen S \& Chan FL 2008 Orphan nuclear receptor estrogen-related receptor-beta suppresses in vitro and in vivo growth of prostate cancer cells via p21(WAF1/ CIP1) induction and as a potential therapeutic target in prostate cancer. Oncogene 27 3313-3328. (https://doi.org/10.1038/sj. onc.1210986)

Yu S, Xu Z, Zou C, Wu D, Wang Y, Yao X, Ng CF \& Chan FL 2014 Ion channel TRPM8 promotes hypoxic growth of prostate cancer cells via an O2-independent and RACK1-mediated mechanism of HIF1alpha stabilization. Journal of Pathology 234 514-525. (https://doi. org/10.1002/path.4413) 
Yuan X, Lu ML, Li T \& Balk SP 2001 SRY interacts with and negatively regulates androgen receptor transcriptional activity. Journal of Biological Chemistry 276 46647-46654. (https://doi.org/10.1074/jbc. M108404200)

Yuan X, Cai C, Chen S, Yu Z \& Balk SP 2014 Androgen receptor functions in castration-resistant prostate cancer and mechanisms of resistance to new agents targeting the androgen axis. Oncogene 33 2815-2825. (https://doi.org/10.1038/onc.2013.235)

Zou C, Yu S, Xu Z, Wu D, Ng CF, Yao X, Yew DT, Vanacker JM \& Chan FL 2014 ERRalpha augments HIF-1 signalling by directly interacting with HIF-1alpha in normoxic and hypoxic prostate cancer cells. Journal of Pathology 233 61-73. (https://doi.org/10.1002/path.4329)

Received in final form 12 October 2017

Accepted 17 October 2017

Accepted Preprint published online 17 October 2017 